\title{
Princípios teórico-metodológicos para elaboração de material didático de PLE e a necessidade de inclusão sistemática dessa discussão nos currículos de formação de professores
}

Theoretical-methodological principles for the elaboration of didactic material of PLE and the need for systematic inclusion of this discussion in teacher training curricula

Iranildes Almeida de Oliveira Lima

Universidade Estadual de Feira de Santana

Feira de Santana, Bahia, Brasil

Luana Moreira Reis

University of Pittsburgh

Pittsburgh, Pensilvânia, Estados Unidos

Resumo: Este artigo discute sobre os conceitos de material didático, apresenta os princípios teóricos e metodológicos que norteiam a elaboração de material didáticos no âmbito de um programa de ensinoaprendizagem de línguas na Universidade Estadual de Feira de Santana (UEFS) e, com base na análise de fluxogramas e ementas de disciplinas dos cursos de licenciatura em letras de universidades brasileiras, destacamos a necessidade de que se inclua essa discussão nos cursos de formação de professores de línguas.

Palavras-chave: Material didático. Conceitos. Princípios Teóricos e Metodológicos. Ensino-aprendizagem de línguas. Formação de Professores de Línguas.

Abstract: This paper discusses the concepts of didactic materials, present the theoretical-methodological principles that guide the elaboration of material within the scope of a language teaching-learning program at UEFS and, based on the curriculum analysis from Brazilian universities, we point out the need to include this subject in the undergraduate courses.

Keywords: Didactic Materials. Concepts. Theoretical and Methodological Principles. Language Teachinglearning. Undergraduate courses.

*Mestre em Linguística Aplicada, estudante de doutorado na Universidade de Alcalá de Henares, Espanha. Professora da Universidade Estadual de Feira de Santana. Email: iranlima@hotmail.com.

**Mestre em Linguística e Leitora na University of Pittsburgh. Email: luanamreis@yahoo.com.br 


\section{INTRODUÇÃO}

A globalização avança a todos os setores da sociedade e as tecnologias digitais de informação e comunicação facilitam a interação e as negociações entre os mais diversos mundos. Nesse contexto, é preciso conferir especial atenção ao valor das línguas e às necessidades que se configuram a partir daí.

Oliveira (2010, p.21), analisando os mercados linguísticos na nova economia na América do Sul, afirma que uma teoria sobre “[...] o peso das línguas é um instrumento para analisar e formular políticas linguísticas tendo por base a situação de uma língua dentro de um mercado linguístico em comparação com outras". Para o autor, as mudanças no paradigma da economia vêm provocando uma imensa valorização das línguas e maior abertura para o multilinguismo.

Carvalho (2012, p. 459) traça "um panorama de ações na área de políticas linguísticas relacionadas à promoção e ao ensino do português como língua adicional no Brasil e fora do país" e, em concordância com Oliveira (2010), assegura que outra característica dessa nova configuração da economia é a composição de redes e associações de países. A União Europeia, BRICS, UNASUL, MERCOSUL, as redes de empresas interessadas no mundo ibérico e nessas associações de países, por exemplo, vêm demandado a formação de profissionais cada vez mais articulados com as possibilidades de comunicação, interação e negociação em diferentes línguas, capazes de lidar com as exigências da natureza complexa do século XXI.

Oliveira (2010) chama a atenção também para a importância das ações de reciprocidade nessa nova configuração mundial. Os acordos de ensino-aprendizagem de português e espanhol firmados entre Brasil e Argentina, agora ameaçados pela nova configuração política do Brasil e pelas consequentes mudanças nas leis da educação brasileira, são um exemplo dessa reciprocidade. Essas ações provocaram demanda de formação de professores e exigiram dos estados brasileiro e argentino uma ampliação da oferta de Licenciaturas em língua espanhola e língua portuguesa, respectivamente. Carvalho (2012) também chama a atenção para essas políticas bilaterais entre Brasil e Argentina e para as ações destinadas à formação de uma região bilíngue, como o desenvolvimento e aplicação de certificados de proficiência e o Projeto de Escola Intercultural Bilíngue de Fronteira (PEIBF).

Essas ações, aliadas às políticas públicas de internacionalização das universidades, aos projetos de democratização do acesso ao conhecimento internacional e aos programas de mobilidade de pessoas e de intercâmbio de conhecimentos têm contribuído para o aumento da procura pelo ensino-aprendizagem de português e vêm delineando novas exigências. Uma delas é a formação de professores. No âmbito de Português como língua estrangeira (PLE), essa demanda tem exigido implementação de mudanças nas Licenciaturas em Letras para a inclusão de discussões sobre PLE ou até mesmo a criação de Licenciaturas em PLE. Na Universidade Estadual de Feira de Santana (UEFS), não há, no momento, discussões sobre a implementação de uma licenciatura em PLE. Não obstante, os cursos de Letras Português e Espanhol, Português e Inglês e Português e Francês vêm passando por mudanças que incluem a criação de componentes curriculares 
que fomentarão discussões sobre o processo de ensino-aprendizagem de PLE. A primeira experiência de ensino-aprendizagem de PLE na UEFS surgiu de um projeto de extensão criado e desenvolvido dentro do Programa Portal: ensino-aprendizagem de linguas para a cidadania, inclusão social e diálogo multi e intercultural. A primeira turma foi em 2011, em atenção à demanda de estudantes do ensino médio em situação de intercâmbio em Feira de Santana, e as posteriores surgiram, principalmente, dos Programas de Mobilidade Estudantil da UEFS e dos Programas de Pesquisa e Pós-Graduação.

Outra exigência que vem se delineando é a de material didático de PLE. Nesse sentido, o Brasil ainda incorre na precariedade e há poucos projetos de elaboração em andamento. Entre os mais conhecidos até o momento, mencionamos o Portal do Professor de Português Língua Estrangeira / Língua Não Materna (PPPLE), uma plataforma online criada sob a coordenação do Instituto Internacional da Língua Portuguesa (IILP) que disponibiliza gratuitamente materiais didáticos elaborados por profissionais de diversos países da CPLP. Outro, mais recente, é o projeto de elaboração de material didático de PLE/PLA que vem sendo desenvolvido por uma equipe formada por diversos especialistas de diversas universidades brasileiras credenciadas no Programa Idiomas sem Fronteiras (IsF) do MEC. Esse material, elaborado colaborativamente, será utilizado por todos os Núcleos de Línguas das Universidades vinculados ao IsF, mas já há previsão de disponibilização para outros contextos. De fato, no âmbito do IsF, já se está trabalhando na criação de cursos online interinstitucionais que levam em conta a diversidade de contextos de uso da língua portuguesa, que já possui demanda internacional. Outras propostas interessantes de análise e elaboração de material didático são encontradas em dissertações de mestrados, teses de doutoramento, artigos científicos.

É por essa escassez de material didático de PLE que muitos programas de ensinoaprendizagem de línguas das universidades e professores, de modo geral, têm se dedicado à elaboração do próprio material didático. No âmbito do Programa Portal: ensinoaprendizagem de línguas da UEFS, essa dificuldade também nos instigou a elaborar nosso próprio material didático. Para tanto, em primeiro lugar, formamos uma equipe com os interessados em participar do processo, definimos pautas de discussões teóricas e estabelecemos o constructo teórico-metodológico que norteia a proposta. Em segundo lugar, determinamos os princípios orientadores de qualquer processo de elaboração de material didático dentro do Programa. Em terceiro lugar, iniciamos o processo de elaboração propriamente dito. Em quarto lugar, avaliamos o processo. O resultado dessa avaliação nos impôs debruçar sobre os currículos de letras para avaliar em que medida eles contribuem para a formação de professores com competências para empreender análise, elaboração e avaliação de materiais didáticos.

\section{PRESSUPOSTOS FUNDAMENTAIS PARA ELABORAÇÃO DE MATERIAL DIDÁTICO DE PLE}

Elaborar materiais didáticos envolve um processo importante de auto(re)conhecimento identitário do professor como pesquisador e agente crítico, autônomo 
e criativo. Em vista disso, é de fundamental relevância inserir as bases teóricas para o delineamento do conceito e para a elaboração de materiais didáticos nos espaços de discussão e formação coletiva de professores. Concordamos com Mendes (2012), quando ela afirma que

\begin{abstract}
Desse modo, mais do que desejamos um material ideal, o que devemos buscar é o material que possa se ajustar a variados contextos e necessidades de aprendizagem, visto que está centrado nos sujeitos em interação e não em programas ou padrões estabelecidos previamente, sem qualquer reflexo no que fazemos quando ensinamos e aprendemos línguas. Por isso, o material didático, tal como o defendo, deve apresentar um tipo de estrutura que funcione, antes de tudo, como suporte, apoio, fonte de recursos para que se construam, em sala de aula, ambientes propícios à criação de experiências na/com a língua-cultura alvo (MENDES, 2012, p. 366-367).
\end{abstract}

\title{
2.1 CONCEPÇÃO DE LÍNGUA
}

Uma tese clássica da Análise do Discurso é que "o sentido de uma palavra (bem como de um enunciado) depende do posicionamento de que o discurso emerge, ou querendo, da posição discursiva do seu enunciador" (POSSENTI, 2016, p. 1094). A variação conceitual de determinados termos no discurso especializado é um exemplo disso. Ferdinand Saussure estabelece que língua "é um produto social da linguagem humana e, ao mesmo tempo, um conjunto de convenções necessárias, adotadas pelo corpo social para permitir o exercício dessa faculdade nos indivíduos" (SAUSSURE, 2006, p. 17). Ele propôs a separação entre langue e parole e assegurou que a materialidade da língua, a fala, "jamais é feita pela massa, é sempre individual e dela o indivíduo é sempre senhor". Da mesma forma, também, considerava que qualquer mudança na língua era o sistema quem a operava, jamais o indivíduo. Esse é um dos aspectos mais controversos da teoria Saussureana, posteriormente, criticada por diversos linguistas que discordavam dessa ideia.

Noam Chomsky, em consonância com os seus propósitos científicos, também defende uma perspectiva racionalista em sua concepção de língua. Para ele, a língua é um mecanismo cognitivo computacional que possui uma estrutura sintática hierárquica em seu núcleo (CHOMSKY et al 2014). Ela dispõe de um componente inato, denominado competence, e um componente relacionado com o uso, denominado performance. Nesse sentido, as ideias saussurianas e chomskyanas se assemelham: ambos defendem uma perspectiva de que a língua possui um caráter mentalista, ao tempo em que também se constitui como um elemento de caráter social.

Por outro lado, Émile Benveniste apresenta uma concepção de língua que expressa uma ruptura com os ideais racionalistas. Para ele, não há sentido considerar o homem separado da linguagem e, portanto, não há sentido negar a importância do sujeito na língua como constructo humano. Segundo Benveniste (1995, p. 293), "a língua enquanto assumida pelo homem que fala, e sob a condição de intersubjetividade, é a única que torna possível a condição humana”. 
Mikhail Bakhtin concorda com Saussure que a língua é um fato social, mas discorda de concebê-la como um sistema abstrato, organizado, homogêneo, desvinculado de valores ideológicos e dissociado do sujeito que a fala. Para Bakhtin (1997, p. 124), a língua vive e evolui historicamente na comunicação verbal concreta, não no sistema linguístico abstrato das formas da língua, tampouco no psiquismo individual dos falantes.

Da mesma forma, Rajagopalan $(2003,27)$ assegura que o conceito clássico de língua apresenta problemas na medida em que "não só abriga a ideia de autossuficiência, mas também faz vistas grosas às heterogeneidades que marcam todas as comunidades de fala". Ele afirma que concorda com "Flairclough (1992) que, dessa forma, a língua é abordada como ela poderia ser num mundo ideal e paradisíaco e não como ela de fato é em nosso mundo vivido".

Makoni e Meinhof (2006) discutem sobre o conceito de língua no contexto da África. Para eles, essa discussão não pode prescindir da consideração de fatores históricos de colonização, dominação e opressão. Tampouco pode se esvaziar de questões sociais como modos de vida ou de diferentes formas de perceber o mundo. Ou ainda, desconsiderar a realidade de um multilinguismo muito peculiar, no qual a coexistência de uma multiplicidade de línguas gera fenômenos em que as pessoas se comunicam em línguas estruturalmente diferentes, mas têm a percepção de que se comunicam na mesma língua. Sendo assim, para os autores,

\footnotetext{
Língua é uma invenção, uma construção, exatamente como outras categorias como o tempo. Ao falar de tempo como construção, não se contesta o fato geográfico de que a terra gira em torno de um eixo, mas isso implica dizer que a significação do tempo tem uma base social e variável. De modo similar, o que é socialmente construído nas línguas é "uma língua" e não a categoria natural, "língua". É importante distinguir entre aspectos "naturais" sobre a língua daqueles que são resultado de intervenções culturais. Uma capacidade para a "linguagem" é natural aos humanos, mas as "línguas" são produto de intervenções sociais e históricas. (MAKONI E MEINHOF, 2006, p. 193).
}

Assim, ao se propor a elaboração de materiais didáticos para o ensino-aprendizagem de línguas, faz-se necessário deixar claro o que entendemos por língua. Dessa forma, considerando que o nosso escopo - o processo de ensino-aprendizagem de línguas - é de natureza complexa e envolve sujeitos que vivem, convivem e interagem no mundo com toda sua complexidade e contradições. A concepção de língua com a qual concordamos não apenas envolve seus aspectos naturais - que evidentemente possuem sua importância - mas também a vincula à cultura, a valores ideológicos, relações de dominação, poder e opressão, à expressão de identidades, ao empoderamento do sujeito e ao exercício da cidadania. Língua é, portanto, uma construção social, concordando com Makoni e Meinhof (2006). É também uma realidade física, histórica, política e cultural que, conforme Benveniste (1995) e Bakhtin (1997), está diretamente associada ao sujeito que a usa. Nessa perspectiva, o processo de ensino-aprendizagem de línguas não deve dissociar-se do compromisso de formação do cidadão crítico, reflexivo, consciente de si como cidadão no mundo, sem perder de vista o outro. Se possível, um cidadão interculturalmente competente capaz de conviver, negociar, interagir, resolver problemas, 
viver no e com o mundo inegavelmente globalizado e comunicativamente quase instantâneo, exercendo sua cidadania.

\subsection{CONCEPÇÃO DE MATERIAL DIDÁTICO}

Ao se falar em material didático pensamos, na maioria das vezes, no livro didático. Mas isso não é por acaso. Com frequência ele é o principal, senão o único elemento facilitador do processo de ensino-aprendizagem nas salas de aula. É um dos materiais que mais tem despertado a atenção dos estudiosos. Como demonstra Vilaça (2009, p. 3), "a maior parte dos trabalhos sobre materiais didáticos publicados em livros sobre ensinoaprendizagem de língua estrangeira discute critérios para a análise e avaliação dos livros didáticos”. Além disso, nos currículos dos cursos de formação de professores, é escasso encontrarmos propostas de discussões que tratam o material didático de forma conceitual, tipológica e mais aprofundada. Apenas nos níveis de mestrado e doutorado, existe uma preocupação maior com as questões epistemológicas e uma visão mais plural sobre material didático.

Diferentes concepções sobre material didático já foram estabelecidas. Algumas tendem a vinculá-lo às ações do professor e à sala de aula com a finalidade de facilitar a aprendizagem nesses espaços de aprendizagem. Outras já são mais amplas, como a de Tomlinson (2013), que reforça a ideia de que existe no mundo uma infinidade de materiais didáticos que podem ser usados para o ensino-aprendizagem de línguas. Para ele,

\footnotetext{
Os materiais incluem qualquer coisa que possa ser usada para facilitar a aprendizagem de uma língua. Podem ser linguísticos, visuais, auditivos ou sinestésicos, e podem ser apresentados em papel, através de apresentações ao vivo ou em cassete, CD-ROM, DVD ou na internet. Podem ser instrucionais, experienciais, elicitativos ou exploratórios, já que podem informar os alunos sobre a língua, podem proporcionar experiência da língua em uso, podem estimular o uso da linguagem ou podem ajudar os alunos a fazer descobertas sobre o idioma por si mesmos. (TOMLINSON, 2013, p.2, grifo nosso)
}

Já Littlejohn (2012, p.283) defende que "materiais são artefatos culturais, não menos enraizados em um determinado tempo e cultura do que qualquer outro exemplo de atividade humana, e como tal, são moldados pelo contexto em que ocorrem." Sendo assim, os materiais são considerados propostas para ação na sala de aula, mas que, ao mesmo tempo, respondem às influências do contexto social de fora das salas de aula.

Assim sendo, os materiais didáticos são elementos culturais, de natureza diversa, que podem ser utilizados para facilitar o processo de ensino-aprendizagem. Esse, por sua vez, acontece nos espaços formais de ensino como os conhecemos, ou fora deles, através de um processo de interação de natureza complexa que envolve sujeito-sujeito, sujeitomundo-sujeito, sujeito-conhecimento-sujeito. A produção de material didático consiste numa prática social, cultural e historicamente situada. 


\subsection{ABORDAGEM DE ENSINO DE LÍNGUAS}

Outro aspecto que precisa ser definido ao elaborar material didático é a abordagem de ensino-aprendizagem de línguas que se adotará. É ela que orienta as práticas pedagógicas dos sujeitos envolvidos no processo e define os papéis de cada um.

Dentre as diversas abordagens existentes, o enfoque denominado Ensinoaprendizagem Baseado em Competências (EBC) norteia as práticas pedagógicas dentro do Programa Portal: ensino-aprendizagem de línguas da UEFS, desde 2008. Consiste numa "perspectiva na qual se estabelecem as competências que se pretendem desenvolver e se fundamenta em um sistema de ensino-aprendizagem que vai progressivamente promovendo o desenvolvimento holístico dos indivíduos envolvidos" (VILLA Y POBLETE, 2010, p. 29).

Nesse sentido, o fim que se persegue nos cursos de línguas do Programa Portal é o desenvolvimento da competência comunicativa e consideramos que essa, por sua vez, está associada a outras competências como a discursiva, pragmática, linguística, sociolinguística, intercultural, estratégica, afetiva e crítico-reflexiva. Essas competências já foram amplamente discutidas por Celce-Murcia (2008), Souto Franco e Almeida Filho (2009), entre outros, mas não propostas nessa ordem como o fazemos.

\subsection{APRENDIZAGEM COOPERATIVA E COLABORATIVA}

Outro aspecto a definir é o enfoque metodológico que engendrará o uso do material. Johnson, Johnson e Smith (2006) afirmam que o aprendizado cooperativo consiste no uso educativo de pequenos grupos de forma a provocar que os estudantes trabalhem juntos para maximizar seu próprio aprendizado e o de cada um dos membros do grupo. Essa maximização do aprendizado em coletivo acontece quando, no momento da interação e da busca do êxito mútuo, os estudantes têm atitudes positivas tanto para colaborar com o outro naquilo que se sentem seguro, quanto para aceitar a colaboração do outro em suas dificuldades.

O trabalho em duplas ou pequenos grupos potencializa os momentos de interação e favorece a comunicação advinda de necessidades reais dos estudantes. Através dessa interação, os envolvidos podem dar-se conta do que realmente são capazes de fazer usando língua, bem como conscientizar-se de suas limitações. Além disso, é nos pequenos grupos que se tem a oportunidade de lançar mão de estratégias para superar algum ruído na comunicação ou de controlar a ansiedade muito comum quando se está em processo de aprendizagem de uma nova língua.

Torrego e Negro (2012) apresentam uma proposta de estruturação da interação em pequenos grupos através de métodos e técnicas como: tutorias entre iguais, ou seja, duplas que ensinam e aprendem; provocação de partilha de conhecimentos prévios, troca de turnos numa conversa, entrevistas a três, entre outros, muito úteis para a elaboração de material didático baseado no trabalho cooperativo e colaborativo. Contudo, aprendizagem cooperativa e colaborativa requer a consideração de alguns aspectos fundamentais para que seja realmente efetiva. 
De acordo com os princípios propostos por Johnson, Johnson e Smith (2006) e com experiências de utilização do trabalho cooperativo e colaborativo como base metodológica dentro do Programa Portal, verificamos que, para que se tenha êxito, é fundamental, entre outras coisas: a) sensibilização para trabalhar cooperativa e colaborativamente; b) atitude de respeito diante das diversidades e das diferenças; c) reflexão sobre o que se vai aprender; d) planejamento de como se pode desenvolver atividades propostas, ampliar a própria aprendizagem e aprendizagem do grupo; e) responsabilidade individual e com o coletivo; f) atitude instigadora, crítica, responsiva ativa e dialógica diante do conhecimento; g) interação voluntária; h) interação cara a cara; i) uso de habilidades interpessoais, de gestão de pequenos grupos e resolução de problemas; j) motivação para o uso das tecnologias digitais da informação e comunicação; k) avaliação do desempenho do grupo e autoavaliação de cada membro sobre o que fez e o que pode fazer melhor para o crescimento do grupo; l) avaliação e reflexão sobre o que se aprendeu, como se aprendeu e redefinir estratégias.

\subsection{INTERAÇÃO COMPLEXA: SUJEITO-SUJEITO/ SUJEITO-MUNDO- SUJEITO/ SUJEITO-CONHECIMENTO-SUJEITO}

É consenso entre os estudiosos que existe no processo de ensino-aprendizagem de línguas estrangeiras a interação entre professor-aluno e aluno-aluno. No entanto, a ideia de interação entre aluno-material ou aluno-conteúdo ainda é restrita aos estudos sobre elaboração de material didático para a EAD. Esse conceito se fundamenta na Psicologia histórico-cultural de Vygotsky (2001), que descreve a Zona de Desenvolvimento Proximal e prevê a concepção de interação sujeito-signo. Do ponto de vista pedagógico, podemos apoiar-nos no conceito de enunciado como unidade da comunicação discursiva proposto por Bakhtin (2003).

\footnotetext{
De fato, o ouvinte que recebe e compreende a significação (linguística) de um discurso adota simultaneamente, para com este discurso, uma atitude responsiva ativa: ele concorda ou discorda (total ou parcialmente), completa, adapta, apronta-se para executar, etc., e esta atitude do ouvinte está em elaboração constante durante todo o processo de audição e de compreensão desde o início do discurso, às vezes já nas primeiras palavras emitidas pelo locutor. [...] O que acabamos de expor vale também, mutatis mutandis, para o discurso lido ou escrito. A compreensão responsiva nada mais é senão a fase inicial e preparatória para uma resposta. (BAKHTIN, 2003, p. 291)
}

Essa atitude responsiva ativa que o sujeito mantém frente ao discurso lido, escrito, ouvido, em sendo considerada no processo de ensino-aprendizagem de línguas, nos espaços presenciais, pode ser de valia inestimável porque garante ao aprendente respaldo para o desenvolvimento de sua autonomia para aprender ou ampliar a própria aprendizagem, estende o campo de alcance do processo de ensino-aprendizagem para além da sala de aula e modifica o referente de quem ensina, que passa não ser exclusivamente o professor. Nessa perspectiva, o papel do material didático é provocar essas interações. 


\section{PRINCÍPIOS PARA ELABORAÇÃO DE MATERIAL DIDÁTICO DE PLE}

Com base nos referenciais teóricos adotados e acima descritos, elaboramos os princípios que norteiam a elaboração de material didático no Programa Portal: ensinoaprendizagem de línguas. Leffa (2007, p. 15) afirma que esse processo envolve no mínimo quatros aspectos: (1) análise, (2) desenvolvimento, (3) implementação e (4) avaliação, que se configuram como um processo cíclico. O que propomos abaixo reflete, em parte, o que Leffa (2007) estabelece como necessário ao processo de elaboração de material didático:

$1^{a}$ Fase - questões preliminares:

a) Avaliar as necessidades;

b) Descrever o perfil do usuário e definir o nível do material;

c) Discutir sobre a finalidade do que se quer ensinar/aprender - a língua - para se determinar a finalidade do material;

d) Escolher os temas geradores de discussões e de interesse geral;

e) Definir o tipo de material que se pretende desenvolver;

f) Estabelecer os pressupostos teóricos e metodológicos norteadores;

g) Selecionar os meios tecnológicos que serão utilizados em sua materialização;

h) Definir padrões de edição;

$2^{\mathrm{a}}$ Fase - Elaboração do material:

a) Retomar a finalidade da aprendizagem da língua para estabelecer as competências que serão desenvolvidas;

b) Apresentar na primeira parte do material as competências que se pretendem desenvolver;

c) Apresentar nas atividades uma visão dinâmica, democrática, política, social, intercultural e pluricêntrica de língua;

d) Fomentar o respeito às diversidades;

e) Fazê-lo aberto, dinâmico e dialógico, de maneira que permita aos estudantes levarem as suas narrativas e o mundo para a sala de aula e com eles estabelecerem diálogos multi e interculturais;

f) Sugerir o uso de redes sociais educativas para a criação de comunidades de aprendizagem online, bem como a visita a sites;

i) Provocar o desenvolvimento do pensamento crítico reflexivo;

j) Demonstrar no material que a aprendizagem se dá a partir de processos complexos de interação e colaboração, e provocar este tipo de interação: professor-aluno, aluno-aluno, aluno-material/conhecimento/mundo-aluno;

k) Instigar o desenvolvimento da aprendizagem autônoma e promover a reflexão sobre o próprio processo de aprendizagem; 
1) Provocar utilização e criação de outros materiais pelos estudantes como: vídeos, tutoriais, blogs, formulários googledocs, portfólios, diários reflexivos, diários de viagens, entrevistas, reportagens, jornais, revistas, jogos, pinturas, entre outros.

$3^{a}$. Fase - Implementação:

a) Validação;

b) Implementação;

$4^{\mathrm{a}}$. Fase - Avaliação

a) Avaliação;

b) Proposição de mudanças, caso sejam necessárias.

\section{A ELABORAÇÃO DE MATERIAL DIDÁTICO DE PLE E AS LICENCIATURAS EM LETRAS}

Em nossas rodas de conversa para discussão dos antecedentes sobre elaboração de material didático, deparamo-nos com afirmações em artigos científicos que nos provocaram inquietação: "os professores escolhem o livro didático, atendo-se a critérios não muito claros ou superficiais"; "a pesquisa aponta lacunas e dificuldades do professorado da rede pública em selecionar material didático de forma criteriosa"; "nos Projetos de Curso de PLE devemos ter o cuidado de oferecer componentes curriculares como Seleção e Produção de Materiais para o Ensino de PLE”.

Essas afirmações, por sua vez, impuseram-nos alguns questionamentos intrigantes: quem são esses professores? Que processos formativos foram constitutivos de sua competência profissional? Em que medida essas discussões foram provocadas no processo de formação desses sujeitos? Implementamos, então, uma nova pesquisa que, ainda em andamento, revela resultados já bastante orientadores. Seu objetivo fundamental foi avaliar os fluxogramas e as ementas dos componentes curriculares dos cursos de letras para averiguar em que medida as universidades vem contribuindo com o processo de formação de professores com competências para analisar, avaliar e elaborar material didático.

Foram avaliados, até antão, cursos de letras de doze universidades do Nordeste Brasileiro. Nessa fase inicial, em nenhum dos documentos constantes nos Projetos Pedagógicos dos Cursos de Letras Vernáculas, Inglês, Francês, Espanhol analisados encontramos propostas de discussão sistemática sobre materiais didáticos. Algo muito sutil apareceu em ementas do componente curricular Estágio Supervisionado, como, por exemplo, a elaboração de práticas pedagógicas, que fica a cargo do professor conferir uma discussão mais plural ou limitar-se à avaliação de um único material.

No entanto, nas Licenciaturas em Português como Língua Estrangeira de universidades situadas no Nordeste, encontramos essa inclusão sistemática tanto no fluxograma, nomes de componentes curriculares que se propõem a tratar da avaliação e elaboração de material didático, como no corpo das ementas. Isso revela uma preocupação em responder à falta de material didático para o ensino-aprendizagem de 
Português como Língua Estrangeira e a manifestações de expoentes do ensino de PLE, como José Carlos Paes de Almeida Filho, que, em artigos científicos ou em eventos, falam da necessidade de uma atenção especial ao material didático quando da elaboração de projetos de cursos de formação de professores de PLE, ou como alguns preferem, PLA.

\section{CONSIDERAÇÕES FINAIS}

A inclusão sistemática da discussão sobre avaliação e elaboração de material didático nos currículos de formação de professores é uma necessidade. Essa ação certamente fortalecerá a visão do papel do professor como pesquisador capaz de avaliar e/ou desenvolver materiais didáticos para atender às necessidades dos seus diversos contextos de atuação. Favorecerá também o desenvolvimento de competências necessárias para que ele possa gerenciar melhor o processo de ensino-aprendizagem e não o reduzir à complexidade das relações de sala de aula. Instigará a inclusão e valorização dos saberes locais no processo ensino-aprendizagem, atendendo melhor às expectativas de aprendizagem dos estudantes. Mas, não podemos nos esquecer de que o processo de ensino-aprendizagem acontece principalmente fora dos espaços formais. $\mathrm{O}$ mundo com toda diversidade de práticas sociais que envolvem a língua é o maior professor. Os sistemas formais, contudo, ajudam-nos a pôr ordem a essa variedade de informações e abrir a sala de aula para esse mundo.

\section{REFERÊNCIAS BIBLIOGRÁFICAS}

BAKHTIN, M. Estética da criação verbal. Tradução de Maria Ermantina Galvão G. Pereira. 2. ed. São Paulo: Martins Fontes, 2003.

BAKHTIN, M. Marxismo e filosofia da linguagem. Tradução de Michel Lahud e Yara Frateschi Vieira. 8. ed. São Paulo: Hucitec, 1997.

BENVENISTE, É. Problemas de Lingüistica Geral. Campinas: Pontes, 1995.

BOLHUIS, J. J.; TATTERSALL, I.; CHOMSKY, N.; BERWICK, R. C. How Could Language Have Evolved?. Disponível em: < https://chomsky.info/20140826/>. Acesso em: 12 de dez. 2016.

CARVALHO, S. da C. Políticas de promoção internacional da língua portuguesa: ações na américa latina. Trab. linguist. apl. [online]. 2012, vol.51, n.2, pp.459-484. ISSN 2175764X. Disponível em: <http://dx.doi.org/10.1590/S0103-18132012000200010>. Acesso em: 12 de dez. de 2016.

CELCE-MURCIA, M. Rethinking the role of communicative competence. In: Intercultural Language Use and Language Learning. Barcelona, Springer, 2008. 
JOHNSON, D. W.; JOHNSON, R.; SMITH, K. Active learning: Cooperation in the university classroom. Edina, MN: Interaction Book Company, 2006.

LEFFA, V. J. (org.). Produção de materiais de ensino: teoria e prática. Pelotas: Educat, 2007.

LITTLEJOHN, A. Language Teaching Materials and the (very) Big Picture. Electronic Journal of Foreign Language Teaching, vol. 9, p. 283, 2012.

MAKONI, S.; MEINHOF, U. Linguística aplicada na África: desconstruindo a noção de língua. In: MOITA LOPES, L. P. Por uma linguistica aplicada indisciplinar. São Paulo: Editora, 2006.

MENDES, E. Aprender a ser e a viver com o outro: materiais didáticos interculturais para o ensino de português LE/L2. In: SCHEYERL, D. C. M. (Org.); SIQUEIRA, D. S. P. (Org.). Materiais didáticos para o ensino de línguas na contemporaneidade: contestações e proposições. Salvador: EDUFBA, 2012.

OLIVEIRA, G. M. de. O lugar das línguas: A América do Sul e os mercados linguísticos na Nova Economia. Synergies Brésil, no spécial 1, p. 21-30, 2010. Disponível em: < http://gerflint.fr/Base/BresilSPECIAL1/gilvan.pdf.> Acesso em: 20 nov. 2016.

POSSENTI, S. Diferenças condensadas em palavras. Revista de estudos da linguagem, [S.1.], v. 24, n. 3, p. 1075-1099, dec. 2016. ISSN 2237-2083. Available at: < http://periodicos.letras.ufmg.br/index.php/relin/article/view/10959>. Acesso em: jan. 2017.

RAJAGOPALAN, K. Por uma linguística crítica: linguagem, identidade e questão ética. São Paulo: Parábola Editorial, 2003.

SAUSSURE, F. Curso de linguística geral. 26. ed. Tradução de Antônio Chelini, José Paulo Paes e Izidoro Blikstein. São Paulo: Cultrix, 1995.

SOUTO FRANCO, M. M.; ALMEIDA FILHO, J. C. P. O conceito de competência comunicativa em retrospectiva e perspectiva. Revista Desempenho, v. 11, p. 04-11, 2009.

TOMLINSON, B. ed. Developing Materials for Language Teaching. London: GBR: Bloomsbury Academic, 2013.

TORREGO, J. C.; NEGRO, A. (Coords). Aprendizaje cooperativo en las aulas al servicio de una educación de calidad. Cooperar pra aprender y aprender a cooperar. Madrid: Alianza Editorial, 2012.

VILAÇA, M. L. C. O material didático no ensino de língua estrangeira: definições, modalidades e papéis. Revista Eletrônica do Instituto de Humanidades, v. VIII, n. XXX, 2009. 
VILLA, A.; POBLETE, M. (Dir.) Aprendizaje basado en competencias: una propuesta para la evaluación de las competencias genéricas. Bilbao: Universidad de Deusto, 2010.

VYGOTSKY, L.S. Obras escogidas. Tomo II. Madrid: Visor, 2001.

Recebido em: 05/06/2017 Aprovado em: 23/07/2017

Publicado em: 01/02/2018 